\title{
Inspired or Inhibited? Choreographers' Views on How Classical Ballet Training Shaped Their Creativity
}

\section{Lucie Clements \& Sanna M. Nordin-Bates}

To cite this article: Lucie Clements \& Sanna M. Nordin-Bates (2020): Inspired or Inhibited? Choreographers' Views on How Classical Ballet Training Shaped Their Creativity, Journal of Dance Education, DOI: 10.1080/15290824.2020.1744154

To link to this article: https://doi.org/10.1080/15290824.2020.1744154

曲 Published online: 21 Apr 2020.

Submit your article to this journal $\widetilde{x}$

Q View related articles $\longleftarrow$

View Crossmark data $\nearrow$ 


\title{
Inspired or Inhibited? Choreographers' Views on How Classical Ballet Training Shaped Their Creativity
}

\author{
Lucie Clements, PhD CPsychol (10) and Sanna M. Nordin-Bates, PhD CPsychol (1) ${ }^{b}$

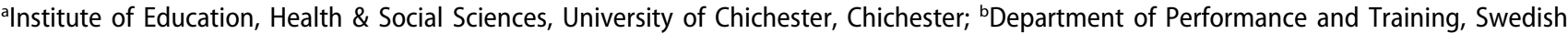 \\ School of Sport and Health Sciences, Stockholm
}

\begin{abstract}
Classical ballet training has been criticized for prioritizing technical excellence over creativity, despite 21st century dancers needing to be strong in both aspects. The aim of this study was to investigate professional choreographers' views on (a) how ballet training inspired vs. inhibited their creativity and (b) potential gender differences in this regard. Eight choreographers $(50 \%$ female) participated in semi-structured interviews, with transcripts analyzed using thematic analysis. The key theme was created from accounts of how ballet training impacted on interviewees' Intrinsic motivation to create, fed into by experiences of Autonomy, Variety and Opportunities. Experiences of significant autonomy thwarting were considered to have inhibited creativity; this was one of several areas of gender difference, and a reason for participants to pursue choreography rather than stay employed as dancers. In following the emergent Recommendations for schools, it is possible that Intrinsic motivation to create could be better nurtured in ballet training.
\end{abstract}

\section{KEYWORDS}

Choreography; ballet; dance; dance science; pedagogy; qualitative research

\section{Introduction}

Professional training in classical ballet is a long and arduous process, steeped in tradition. Auditioning for (pre-) professional training at ages as young as nine, aspiring dancers typically hone their skills for several hours each day, up to six days per week, and for around 10 years before they can hope to join the professional ranks. The exact technical skills to be developed are laid out in training manuals and syllabi as well as passed on via experience. This technical refining is scrutinized especially during daily class, but also in classes focused on pas de deux, repertoire, coaching, rehearsals and, for girls, pointe work. This strong focus on technique aligns with the emphasis on technical excellence, or even perfection, expected of professional dancers.

In the past several decades, the demand for dancers to be not just strong technicians but also creative artists has grown (Clements and Redding 2019). Creativity is defined as behaviors both original and suitable for a particular context (Amabile and Pillemer 2012), and in ballet it can be important on a larger scale (e.g., new choreographies) and on a smaller scale (e.g., co-creating via improvisation; creative approach to a role). Today, ballet companies across the world typically perform a combination of classical and modern/neo-classical works, and dancers are frequently called on to co-create new choreographies. As an example, interviews with artistic directors of major United States ballet companies highlighted how skills related to creativity-including openness, imagination and the ability to make a role one's own-are critical when being considered for promotion to principal rank (Schwab 2016).

The dual demands on dancers to be excellent both technically and creatively are important aims for ballet schools, as made clear in the following words by Dame Ninette de Valois, founder of the Royal Ballet School: "A school is the bedrock of any company, nurturing as it does the dancers and choreographers of the future" (The Royal Ballet School 2020). This is not uncomplicated, however, as strivings for technical excellence and creativity are sometimes in conflict (e.g., Morris 2003; Dyer 2009; Nordin-Bates 2019). For instance, technical drilling is often intensely focused, repetitive practice or imitation of a master model, such as a teacher, within a relatively formulaic class structure. Such training helps safeguard tradition (Salosaari 2001) and may prepare the body for the demands of a dance career (Dyer 2009). At the same time, students may learn to favor technique, tradition, and reproduction at the expense of creativity and artistry (Salosaari 2001; Morris 2003; Gard 2006; Dyer 2009). 
Scholars in this area are often highly critical of the authoritarian legacy of ballet. For instance, Geraldine Morris (2003) argued that the lack of innovative ballet choreographers may arise from the historical focus on technique and associated attitudes. She describes how the teacher-led approach typical of ballet “... prevents dancers from taking control of their training and of their freedom to make knowledgeable interpretations of choreographed dance movement" (Morris 2003, 26). Interestingly, the aspects highlighted as lacking in traditional, authoritarian ballet teaching are often precisely those associated with creativity. These include placing value on individuality, flexibility, reflectivity, open-ended exploration, and there being many ways of doing something "right" (Mead 2009; Watson, Nordin-Bates, and Chappell 2012; Choi and Kim 2015; Weidmann 2018; Clements and Redding 2019; Nordin-Bates 2019).

Recently, one author of this article (Nordin-Bates 2019) proposed that self-determination theory (SDT) (Ryan and Deci 2000), a well-evidenced theory of motivation, may be used to understand how creativity is nurtured or thwarted in ballet education. Resting on a foundation of numerous investigations from sport, exercise, health and education, SDT proposes the existence of three basic psychological needs: autonomy, competence, and relatedness (Ryan and Deci 2000). According to Richard Ryan and Edward Deci (2000), relatedness is about meaningful belonging and may be satisfied via mutually respectful relationships and the valuing of people over products/performances. Competence is about feeling good enough to master a task, and may be satisfied via suitable, individualized challenges and positive, constructive feedback. Lastly, but perhaps of greatest importance when considering creativity, autonomy is about agency and ownership, a sense of being free, and of following one's own path. The need for autonomy may therefore be satisfied via the provision of choice and meaningful rationale, by valuing individuality, and by encouraging reflectivity (see Weidmann 2018 for several ballet examples). Dancers who experience autonomy support from teachers also report higher levels of intrinsic motivation and wellbeing (Quested and Duda 2011), while dancers and teachers report that autonomy support can nurture creativity (Watson, Nordin-Bates, and Chappell 2012; Nordin-Bates 2019). Contrastingly, the need for autonomy may be suppressed or even thwarted through undermining or controlling behaviors (Ryan and Deci 2000).

Both students and teachers in one of our studies perceived autonomy support to be more common in contemporary than in ballet classes, and many struggled to see how the rigor and discipline of ballet training could be combined with individuality and creativity (Nordin-Bates 2019). Indeed, ballet is often portrayed as autonomy-suppressive, with an all-knowing teacher instructing passive, unquestioning students in a culture of black-and-white views on right and wrong (Salosaari 2001; Morris 2003; Jackson 2005; Lakes 2005; Pickard 20122001; Watson, Nordin-Bates, and Chappell 2012; Barr 2013; Alterowitz 2014; Barr and Oliver 2016).

The issues introduced above combine to present an interesting predicament. Specifically, if traditional pre-professional or classical ballet training thwarts creativity, what characterizes those who actually do make it into that distinctly creative job of choreographer? What aspects of training set them up for this career? Perhaps they were afforded greater autonomy than others who did not become choreographers. Alternatively, are they perhaps succeeding in choreography in spite of their training, rather than thanks to it? To explore these notions, we investigated how successful dancers-turned-choreographers perceived their own training in pre-professional classical ballet. Given the close links between autonomy and creativity identified in the literature, we paid special attention to autonomy.

\section{Ballet, Autonomy, and Potential Gender Differences}

In ballet, females are typically seen as central or iconic, and presented as the pinnacle of flawless perfection. Moreover, females often outnumber males ten, or even twenty, to one except at the very highest levels (i.e., professional companies and some top schools; see also Clegg, Owton, and Allen-Collinson 2019). Yet although ballet may outwardly place the female center stage, its decision making, artistic direction, and choreography is strongly male-dominated (Meglin and Brooks 2012; Clegg, Owton, and Allen-Collinson 2016). One aspect of this phenomenon is the disproportionate number of male choreographers-or, a disproportionate representation of female works. Collette Kelly (2017) notes that in a survey of the nine largest US ballet companies, $62 \%$ of dancers were women, while $85 \%$ of choreographers creating work for these companies were men.

In 2020, US based company Dance Data Project (2020) published statistics that of 22 US ballet companies, 73\% employed exclusively male resident choreographers. Similarly, in international companies, only $13 \%$ of companies hired exclusively women, demonstrating a worldwide trend. Of the nine UK and European companies with resident choreographers, only two employed women. ${ }^{1}$ As a specific example of this in the UK, in 2017, 
Crystal Pite became the first female choreographer to create an original work for the Royal Ballet since 1999.

One potential explanation for this discrepancy is the difference in autonomy afforded to males and females in ballet training. Media reports (e.g., Jennings 2013) and more academic sources have provided accounts of how females in ballet are expected to be passive, unquestioning members of a homogeneous corps de ballet (Stinson 2005; Lehikoinen 2006; Meglin and Brooks 2012; Clegg, Owton, and Allen-Collinson 2017; Kelly 2017). Contrastingly, males in training are often seen as more individual and daring, more likely to experiment, and even challenge the traditional, authoritarian pedagogy. As a result, teachers may adopt a more empowering (i.e., autonomy supportive) approach, which supports the creativity of males more than that of females (Clegg, Owton, and AllenCollinson 2016, 2017, 2019). Media have also reported professional female dancers fearing loss of work for being outspoken, while their male counterparts would be lauded for their independence and "maverick attitudes" (Jennings 2013). In the present paper, we present first-hand accounts from four female and four male professional choreographers regarding these phenomena. To do so, we gathered their experiences of ballet training, including perceptions of autonomy support, via in-depth interviews.

In summary, the aim of the present study was to examine choreographers' views on how their own classical ballet training inspired and/or inhibited their creativity and emergence into professional choreography. We focus on schools which provide academic tuition alongside the dance training and expect students to be placed in world-class ballet companies upon graduation. Given indications that the training of men and women in ballet may differ, we also explored whether these choreographers perceived any gender differences in the nurture of creativity during their training.

\section{Methods}

\section{Participants}

Eight European choreographers (50\% female) aged 28-42 years old participated. All had undertaken fulltime education in an upper-level, classical ballet school between the ages of approximately 15-18 years, some in their home country and some as international students. Most had also trained in a lower-level school before that (approximate ages 11-14). The schools included the top British schools (Royal Ballet School, English National Ballet School, Elmhurst, Tring Park) and the Swedish Royal Ballet
School, though participants also had roots or training experiences from other countries. Some had remained in the same lower and upper school, whilst others had moved to a new location for upper school. These schools provided academic tuition in addition to ballet training, and many students boarded.

After leaving training, all participants had been employed by at least one professional ballet company. At the time of their interviews, five participants (three male, two female) were no longer employed as performers and were working as freelance choreographers, often complemented by other smaller creative and teaching positions. The remaining three combined choreographic work with employment as ballet dancers. All had experience with choreographing for one or several major international ballet companies as well as smaller contemporary and/or ballet companies, and some were internationally renowned. They choreographed in a variety of classical, contemporary, and neo-classical styles.

\section{Procedures}

We held pilot interviews with two dance lecturers, one in the UK and one in Sweden. Both had undergone vocational ballet training and had experience of professional performing, teaching, and choreography. To recruit de facto participants, we used stratified sampling by devising a list of potential recruits and contacting each through publicly available e-mail addresses and/or personal websites. In the latter stages, we recruited some participants via recommendations from other interviewees. Given the partial research focus on gender, we recruited equal numbers of men and women.

The study was granted approval by an institutional ethics committee, and all participants gave informed consent. Interviews followed standard procedures for ensuring ethical conduct and good quality, including emphasizing interest in individual experiences, encouraging honesty and questions if anything was unclear, the giving of information about confidentiality and the right to stop or not answer a question. We conducted five interviews in person in a quiet space and three over Skype (usually because the participant was in a different country than the interviewer). We digitally recorded the interviews, lasting between 47 to 139 minutes $(M=85)$. . Research has established that Skype interviews can, despite the physical distance between interviewer and interviewee, generate highquality data (Lo Iacono, Symonds, and Brown 2016).

To enable participants to speak openly about their experiences, yet ascertain that interviews remained 
focused on the study's aims, we used a semi-structured approach. Questions were primarily open-ended, with clarification and elaboration probes used as needed (Patton 2002). The interview guide included questions about interviewee background; views on creativity (e.g., "In your experience, where does creativity come from?"), facilitative and inhibiting experiences of creativity nurture (e.g., "Can you give examples of any opportunities which inspired you or otherwise helped you to develop your creativity?" "Can you give examples of any aspects of dance training which inhibited your creativity?"), recommendations for training creativity (e.g., "If you were to give recommendations for ballet teachers and schools on the nurture of creativity, what would they be?"), and the potential role of gender (e.g., "Do you have any personal examples of how you were treated either the same, or differently, as other males and females during your training?"). Recruitment and subsequent rapport with participants were aided by both authors being active in dance psychology research and practice since many years.

\section{Analysis}

We transcribed the interviews verbatim and analyzed them in NVivo (QSR International 2014) using a predominantly inductive thematic analysis (Braun and Clarke 2006). We deductively coded some aspects of the analysis based on the literature review, however, and in line with our expertise on creativity, perfectionism and motivation theory. To enhance trustworthiness, the first author led the analysis and the second author acted as a critical friend regarding initial coding of the first interview, and again after the third interview had been analyzed.

During analysis, we took care to acknowledge that the rapport between us as female interviewers and female interviewees may have differed to that of us and male interviewees. This was particularly important during conversations around gender differences, which may have resulted in gender-based differences in participant openness, or perception of threat. To overcome this, we took steps to ensure that a fair representation of experiences were presented in the final analysis. In the results section, we use pseudonyms to preserve anonymity, in line with our standard practices as psychologists and the wishes of some participants.

\section{Results and Discussion}

The results demonstrated a complex relationship between vocational ballet training and the development of creativity, with participants speaking in depth about the ways in which training had inspired but, to a slightly greater extent, inhibited their creativity. Still, all recognized the importance of a classical ballet foundation for their subsequent careers. For instance, Hugo explained that in his vocational school: "I don't think that they fostered creativity, but what it did give me was a really good understanding of dance as a vocabulary."

Many similar participant experiences emerged, resulting in the overarching theme Intrinsic motivation to create. Feeding into this were three key themes: autonomy, variety, and opportunity, each of which was seen to nurture intrinsic motivation to create. Importantly, themes all interacted in multiple ways, a sense of which is provided by Hugo:

You have this perfect storm of things. So, you have maybe a really influential individual: maybe a parent, maybe a teacher. That's always there. There's an accident of geography, where you have access to things. But there's nobody that succeeds in anything without doing it themselves. There's no coach, teacher, anywhere in the world that can make you do it. You have to do it.

Within each of the three key themes was the recurring through-line of recommendations for schools; that is, participants offered recommendations for schools regarding each of autonomy, opportunity, and variety. Two additional through-lines also emerged from the data: gender and the decision to pursue choreography. Below, the overarching theme and the key themes which contribute to it are outlined and discussed in turn, with through-lines integrated throughout. For a visual representation, please see Figure 1.

\section{Intrinsic Motivation to Create}

Participants demonstrated a strong internal drive to create which had endured through childhood, training and their careers. This was particularly emphasized in the females' perspectives and decisions they had made to ensure that their desire to create could be fulfilled. Below, the three sub-themes of childhood creativity, interest and enjoyment, and persistence are outlined, the through-line of gender emerging in the latter.

\section{Childhood Creativity}

Several participants suggested that their creativity had been present long before their ballet training. Carla clarified that this was not just a love of dance, but of creating dance: "A lot of other kids danced but I was interested not just in improvising but also setting what I'm doing and then actually creating something." 


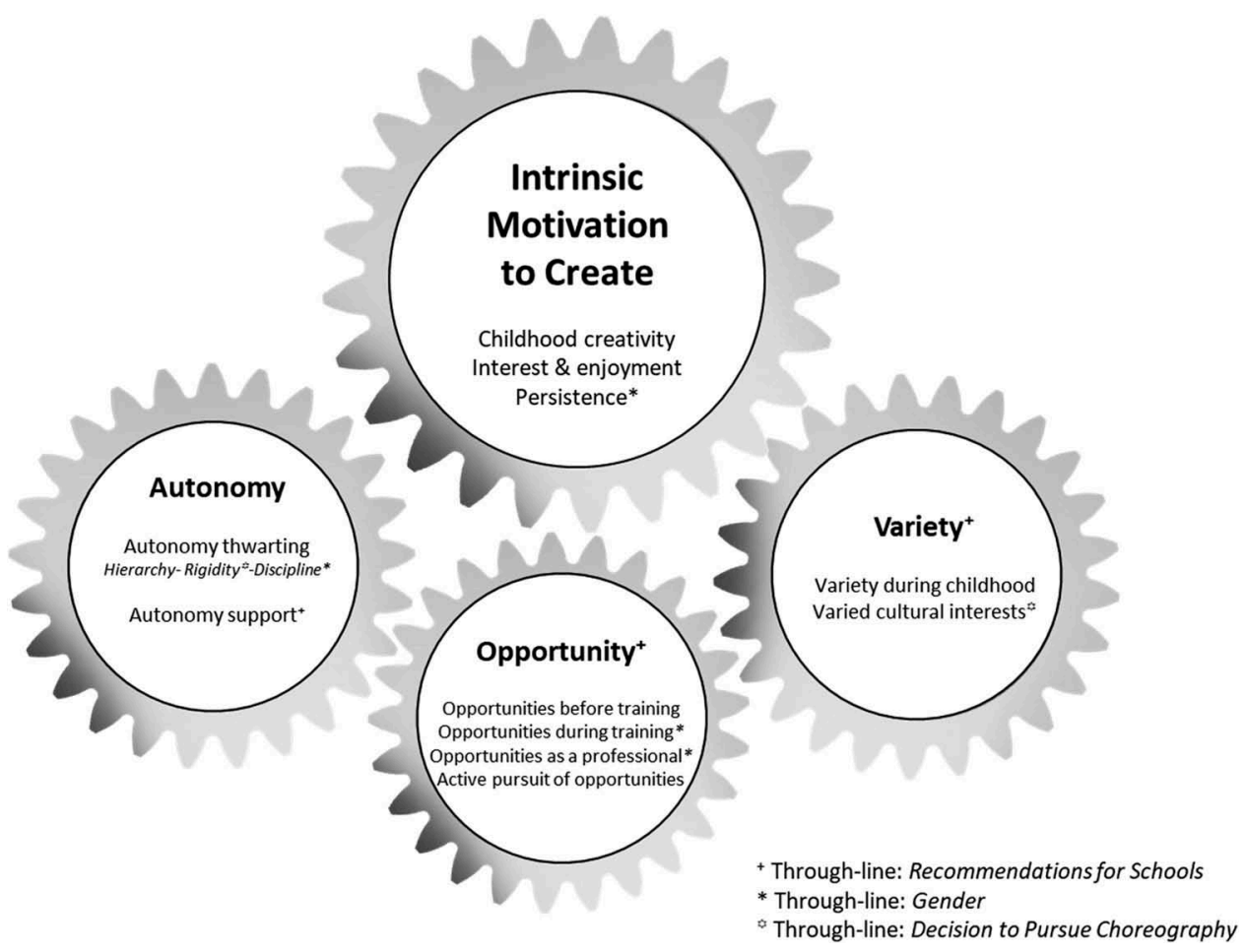

Figure 1. Key themes and interactions between sub themes and throughlines.

\section{Interest and Enjoyment}

All participants described interest and a sense of personal meaning that they, like Bella, "really, really enjoy the process" of creating. Speaking of a director, Eric said: "I approached him to have a conversation with him about choreography 'cos I was getting really excited about it and suddenly, you know, thought: 'this is something I want to do!"”

\section{Persistence}

While all interviewees had been persistent in their careers, it related to the through-line of gender as it appeared particularly strong among the women. For instance, Dina demonstrated her persistence as follows: "So they think that 'She's a girl, she won't be able to do this. She will fail.' I wanted to prove for myself and for the others that I could still do this, even if I was a girl." Anna even recounted how, after having creative successes, "They would then do one not nice thing just to keep me in my place"; yet, she still went on to a successful choreography career. Carla explained how her drive to create enabled her to withstand difficult experiences as a dancer, giving her room to reflect on how she wanted to be as a choreographer:

I was always analyzing, thinking in my rehearsals, "I'm gonna do it like this; I'm not gonna do it like this." It's definitely something that my deep will for choreography has had to fight through with huge willpower.
Huge willpower. "When I get my opportunity, it's not gonna be like this."

Interestingly, Bella noted that men also faced barriers, due to their minority status. She argued that this might encourage persistence in a different way, and thereby support creativity:

Flip it round the other way: I think perhaps the reason that there are more males [in choreography] is because there are less males that go through training so they have to form their own selves and their own resilience, their own confidence a bit earlier ... they will stand out anyway so they have to stand out.

\section{Autonomy}

Autonomy was the most prominent theme, with clear accounts of how autonomy supported creativity, similar to evidence from the workplace (Amabile and Mueller 2007). In line with the argument by Morris (2003), Bella explained how autonomy thwarting can create a barrier to creativity by "Being afraid to experiment and being afraid to put yourself out there and be judged." Two sub-themes emerged: a substantial one regarding autonomy thwarting, and a smaller one regarding autonomy support.

\section{Autonomy Thwarting}

Participants described numerous ways in which autonomy was thwarted during training, which 
strongly resonated with previous research in dance (Salosaari 2001; Morris 2003; Jackson 2005; Lakes 2005; Pickard 2012; Watson, Nordin-Bates, and Chappell 2012; Barr 2013; Alterowitz 2014; Barr and Oliver 2016; Nordin-Bates 2019). This was mainly due to its traditional, authoritarian nature, which included hierarchy, rigidity, and discipline. The through-line of gender emerged in relation to discipline especially, while rigidity was a reason that participants gave for the through-line of the decision to pursue choreography.

Hierarchy. Participants described how the hierarchical nature of ballet training might thwart autonomy. For instance, echoing the sentiments of dancers interviewed by Tansin Benn (2003), George said it was "Because of the traditional repertoire or the way that choreographers and dancers work together, it's very like puppet and puppet master." Hierarchy was also deemed to impact on wellbeing: "You have a whole tradition that's premised on hierarchy and self-worth in relation to that ... people judge themselves very acutely on their perceived status in that hierarchy and that's not very healthy" (Eric).

Rigidity. Numerous examples of the rigidity of ballet training were given, such as when Felix referred to himself as "A tool ... you're being assigned what to do in a very particular way, it's very right-or-wrong." A direct consequence was a lack of choice and flexibility. For instance, Hugo explained that in school "They wanted people that conformed, they wanted people where your leg would be at this height, your arm would be in this position, this is how you do an assemblé. And there was no flexibility." Bella even stated that "I realized that actually you can't be that creative as a dancer because you have to do what you're told". Some described how autonomy was directly thwarted by teachers: "The feedback I got from the teachers was 'This isn't the kind of music you should be choreographing to' and so I think it just put me off" (Eric). After his training, Eric felt that its rigor had limited his creativity:

My body had been completely informed by this very rigorous process that instils a very specific knowledge of movement in it but not a great deal of freedom to think around it. Not an attitude or an understanding of how to think creatively around it.

Dissatisfaction with the lack of autonomy directly related to the through-line of the decision to pursue choreography. For example, Felix explained that "I do think that's why I left it 'cos it's not really ... I think classical ballet is just not an art form that's about creativity." Similarly, Eric stated that: "It kind of dawned on me, 'Oh-this is going to be my career! I'm just gonna keep on doing these same things again kind of periodically'. And I really didn't like the idea of that".

Discipline. Both positive and negative aspects of discipline were discussed. Positively, participants all recognized the importance of discipline for a ballet career (Dyer 2009). In Bella's words: "It's necessary 'cos it's such a strong technical art, that has to be perfected first, absolutely. You need to be drilled and it needs to be strict and you need to train." Indeed, Felix felt that discipline might even facilitate creativity: "When everything is possible it's a mess. It's much better to be disciplined and, you know, have routine, 'cos that's when you can afford to be creative."

Negative views on discipline emerged in relation to obedience and punishment. This was related to the through-line of gender, as it was specifically strong for females: "The girls get so used to being told what to do, they; they obey. And as a choreographer you have to be someone that doesn't obey" (Dina). This inequality was supported by Eric, who noted that "Young girls are expected to be, generally in society but especially in a ballet training context, that kind of higher level of discipline ... there's a huge amount of bias, I would say." Accordingly, and in line with the sentiments reported by Clegg, Owton, and Allen-Collinson (2016, 2017) regarding a greater sense of autonomy afforded to boys in dance training, he felt that "I think I got away with a lot that, if I was a girl, I wouldn't have." These findings align with previous research which identifies the expectation of female dancers to be passive (Stinson 2005; Lehikoinen 2006; Meglin and Brooks 2012; Kelly 2017). For Carla, gender differences in obedience were keenly felt, and their impact extended beyond creativity thwarting and into downright inefficiency:

It would just drive me absolutely crazy, but some of the girls would stand there for the whole rehearsal and be asked to do things that are just not possible, or doesn't work, but they just won't put up their hand and say anything ... The guys are definitely not like that.

Anna illustrated how discipline was at times so severe that it involved punishment for the slightest misdemeanor: "We wouldn't have jokes with our ballet teacher, I mean there was no chance. ... I got in trouble once for looking down when I said 'Hello' rather than looking her in the eyes." The fear 
emerging in such rigidly disciplined environments was seen as a barrier to creativity. For instance, Carla recounted how "You were so scared in class of doing the wrong step, or the wrong thing, getting told off ... there was such a rigid environment in terms of that." She even gave examples of how, later in her professional ballet career, women in her company took steps to eliminate individuality:

The idea was wear black ... and don't stand out. Just look like the girl next to you as much as possible, be in line. Then you won't get shouted at. You know, if you don't hear your name, it's good.

Loss of individuality, too, was particularly emphasized by females. Anna said:

It's quite different from the way they teach boys, and even the fact that you go into the corps de ballet and are meant to be like one body and not really have too much of a personality. It's preferable, definitely not a voice.

An important challenge for ballet teachers, then, is how to support autonomy while preserving the beneficial aspects of discipline and rigor, particularly when teaching females.

\section{Autonomy Support}

When autonomy support had been experienced, it had a strong positive impact on creativity, as identified in previous research (Watson, Nordin-Bates, and Chappell 2012; Nordin-Bates 2019). For instance, Hugo gave this example of how a guest teacher nurtured his creativity:

I was completely taking the piss [British slang: 'Joking around'], but it was interesting to me to be told that that was ok. And then [out of] all of my training that springs to mind: that's the only time that I think kind of no one shut down my creativity.

In some cases, participants created their own autonomy support by going counter to their training. George explained: "We've got this traditional regimented kind of way of learning ... I think back then I liked to do the opposite, I liked to go against it." He went on to explain that this rebellion facilitated a sense of autonomy and creativity development: "Just moving in my own little way ... I think it did start to develop, that it was a freeing situation that, like, was aside from the training."

\section{Recommendations for Schools: Autonomy Support}

Participants identified the challenges that schools face in supporting both technique and creativity. The following quote from Bella mirrors accounts of dance teachers in previous work (Nordin-Bates 2019):
I think ballet schools have to be very, very careful that because it's about striving for perfection within a technique, that you don't lose the creativity and the sort of individual in that journey. And that you don't get that drilled out of you. You know, worrying that you have to be perfect standing in a line to execute everything perfectly.

Consequently, they spoke of ways in which schools could better inspire creativity by supporting autonomy, for instance by providing choice:

... a couple of moments in an exercise in the center where they can choose their own things or, I don't know; even a position at the end to encourage a way of, just to switch the brain and think of them dancing at what they want to do rather than always being told what to do. (Carla)

Hugo gave an example of how individual input could support autonomy: "I think they should coach solos in a way that's 'this is how it should be done,' but then also work together to see how students feel about how it should be done." Finally, in line with research that emphasizes the importance of reflectivity and open-ended exploration (e.g., Weidmann 2018), Eric suggested looking at ballet from a broader, less traditional, perspective by encouraging, "A kind of active engagement in questioning and in reflection and in a curiosity around what that process of training is, and what the technique of ballet is in relation to other things."

\section{Variety}

Variety was considered crucial in developing creativity, and participants spoke of two sub-themes: variety during childhood and enduring varied cultural interests. The through-line of the decision to pursue choreography emerged in relation to varied cultural interests, and recommendations for schools were offered regarding variety provision.

\section{Variety during Childhood}

Participants spoke of how exposure to different art forms in childhood facilitated creativity. For example, Bella said of her father: "He's really into music so music was always around me as a kid. We'd spend ages sifting through music and finding music for the piece that I'd choreograph." Eric noted how his aunt had encouraged him to keep his dance interests open during training:

I used to go and visit her at weekends and she used to take me to see companies like Rambert and $\mathrm{NDT}^{2}$ and I guess was subtly helping keep my eyes open to other forms of dance. So I definitely have her to thank. 


\section{Varied Cultural Interests}

Broad, enduring interests in the arts were evident among participants, in line with previous findings regarding contemporary dance students who teachers perceived to be the most creative (Clements and Redding 2019). As Felix put it: "Choosing one medium has never really been easy for me, and kind of counter-intuitive." The importance of being engaged and curious was emphasized by Carla:

For me seeing lots of other work, it's what inspires me to adapt my work, see what I could do. To inspire me on pieces that I'm doing ... I guess going to exhibitions and just being really open, to culture.

All of the male participants had strong music interests. Hugo explained how this nurtured his creativity during ballet training: "I used to spend hours at weekends just making music ... half of that was me pursuing the rockstar dream and the other half was writing music for dance. That was the only real creative output." Similarly, Bella noted that keeping variety in her life facilitated her ability to continue as a dancer:

What I always clung onto, which is perhaps why I've ended up being at this point that I am now, as a more creative one, is because I also had lots of other stimulus from outside. So it's keeping it bubbling underneath.

Participants were also inspired by exposing themselves to a variety of literature: "It can be some specific meaning that you remember from a book that you have read. 'Yes, but this can develop to a theme, why not do it on stage?"' (Dina). The openness to different influences meant that some participants saw their creative roles as fluid. George explained it this way:

First and foremost, I see myself as a choreographer and hopefully soon a director of stuff. But for me there's different elements of creativity to access ways of looking at things, so like I'll write a song, or I'll do a bit of poetry, or I'll dance, or I'll put some music on. It's all ways of looking at things.

Relatedly, a perceived lack of variety as a ballet dancer was associated with the through-line of the decision to pursue choreography. Said George of his decision to leave ballet:

I just wanted to step out ... I didn't want to be sort of under that umbrella. So that was much more putting my team together and using different people like dancers, actors; people that were right for the parts rather than going into a company and choosing.

\section{Recommendations for Schools: Variety}

Participants emphasized the importance of variety to nurture creativity in ballet school. For instance, George felt strongly that:
They do need a training that is classical ballet but is supplemented and complementary to other experiences. Whether it's like the choreography stuff, the creativity, the knowledge, the awareness, the awareness of things that feed in to what makes you you, and creative; it's all feeding them as dancers, as artists.

Dina gave a more concrete recommendation when suggesting that schools could, "Mix, have different music, why not? Play jazz, why not test that?"

\section{Opportunity}

In line with research in other domains, all participants identified individuals or occasions when specific opportunities had nurtured their creativity (Cropley 2017). Some explained how a lack of opportunity could prevent creative development. Speaking of a ballet company for which she had choreographed, Dina explained how they were held back creatively because their dancers "Didn't have improvisation in school. They never had the opportunity and it was never a question about experimenting, like "break the rules and do something else."”

Four sub-themes of opportunity emerged: opportunities before training, opportunities during training, opportunities as a professional and active pursuit of opportunities. The through-line of gender emerged in relation to opportunities during training and as a professional, and recommendations for schools were offered.

\section{Opportunities before Training}

Participants spoke fondly of individuals who had provided opportunities during childhood, and how these had opened them up to creativity: "I had a great teacher back home ... she would often allow me to create my own solos or give me like a theme" (Carla). Bella, who had entered full-time ballet training slightly later than the other participants, believed that doing so had helped her by giving her more opportunities: "Cos I wasn't in full-time [ballet school] at 11, I think it meant I got to take a lot of other opportunities that have made me a lot more rounded."

\section{Opportunities during Training}

Opportunities during training were predominantly described in relation to choreographic competitions. As George commented: "I think those competitionsalthough I DO NOT believe in competition-the positive side is opportunity. They gave a platform and an opportunity to set a goal and to create something for that goal." Interviewees supported these events being optional, but they had been keen participants themselves. Carla said: 
" ... it was my time and I loved it and I always got nice feedback from it and it encouraged me to keep going." Interestingly, Anna noted : "When I go back now I think it's quite interesting looking at the board of all the winners and most of us have gone on to choreograph."

The through-line of gender was prevalent regarding opportunities. Eric noted that "Lots of girls won the choreographic competition ... they wanted to choreograph, or when they had the opportunity they did it really seriously and the boys didn't." Hugo reflected differently on this gender disparity:

... it was the eagerness to impress and that thing of, "if there's an opportunity I should take it because it'll look good". And the girls were much more keen to look like they were doing the right thing, like attentive students and working really hard, than the lads were.

\section{Opportunities as a Professional}

Participants gave several examples of how opportunities during their careers had impacted their creativity. Hugo spoke of an individual who provided a break-through moment:

He gave me an opportunity to make a piece there and even though the piece I made was terrible, it's an opportunity to learn ... most of the lessons that I've learned in my attempts at choreography I think come from that single experience: about being ready, about communicating a clear idea, I think having a clear system, which was there beforehand but was really crystallized by that.

Opportunities were sometimes provided via other choreographers' creative processes. Carla gave the following example:

That really pushed me because he was seeing how far he could take classical ballet with what he does, so it was taking me as a dancer to see how far I could push my body. How far can I push my choreography into something else as well? And to see him work as a choreographer was just so inspiring for me.

The through-line of gender emerged here, with some perceiving fewer opportunities for women to pursue choreography early on. Anna suggested this was due to the practical constraints of corps de ballet training: "if we're in the corps we'd be needed for 8 hours and they'd [the men] train for 1 . So they do generally have more time ..." Carla suggested that women had to work harder to gain opportunities:

I had to prove myself a lot before being given that opportunity ... this guy did one workshop and they already gave him opportunities. So it was like "Ah-it wasn't that easy for me" ... there was definitely a moment where I felt like they saw potential in the guys and trusted them and gave them another opportunity; not so much with the girls.

Not everyone agreed with this view; for instance, Bella stated clearly that "Any choreographic opportunity that I have had or I had or pursued has been open to anyone ... at no point was it like 'Ok, men come over here: you're gonna be the choreographers." She went on to explain her frustration with being seen as unique because she is female: "I was in an article 'cos they wanted this thing about female choreographers, and it was like 'Wow we've found one!' As if I'm like some kind of alien, like 'Oh you're a really interesting specimen!'” Both males and females felt strongly that "You should program choreographers because they're good, not because they're male or female" (Hugo).

\section{Active Pursuit of Opportunities}

While opportunity provision was important, participants were by no means passive recipients; instead, they actively pursued opportunities to be creative: "I took chances already in school, when we had them. If we had choreographic workshop or something I always took them, I mean that was like great and it did mean a lot" (Felix). Some also created their own opportunities: "I've always had enough opportunities, but 50\% of them have been offered to me and 50\% I've found" (Anna).

\section{Recommendations for Schools: Opportunities}

Participants felt that providing opportunities at ballet school was crucial. Given their own positive experiences of choreographic competitions and workshops, provision of such was recommended, paralleling recommendations for creativity development in educational contexts (Sternberg 2007; Daly, Mosyjowski, and Seifert 2019). However, interviewees recommended that these should be noncompetitive: "I think the opportunity and then to not judge it. I think the competitions are nonsense" (Hugo). They also suggested that bringing successful choreographers into schools would support budding choreographers: "I think once you get those role models there as well, you know, people can look up to them and think 'well, she's done it so I can do it"' (Anna).

Rounding off our results section by tying several themes together, George offered the following which explains how the provision of opportunities supports autonomy, and therefore creativity:

I believe younger people, choreographers, nurturing young talent is all about opportunity. Giving those opportunities, saying: this is a process! Create something, learn from it, hone your own artistic individual 
muscle of what that is. There are no rights and wrongs ...

\section{Conclusion}

The aims of this study were to examine choreographers' views on how their classical ballet training inspired and/or inhibited their creativity and emergence into professional choreography, as well as the role that gender might play in the relationship between ballet training and creativity. The depth of experience shared by participants provided rich findings in explaining how choreographers' intrinsic motivation to create was fed by autonomy, variety and opportunity. It is clear that a drive to create which persists in the face of the challenging ballet training environment was crucial in the path to choreography.

The study is strengthened by the recruitment of participants who had trained at a similar time during the 1990s and early 2000s, as well as their high esteem. There are, however, a number of limitations of the work. First, all participants had left vocational ballet training over 10 years ago. Not only might recall be unclear, but the environment and approach to preprofessional classical ballet training might have changed, as some participants suggested. Secondly, the results represent mostly choreographers who had trained in the UK; still, no obvious differences were noted compared to participants who had trained in Sweden. Finally, it might be argued that not all schools aim to train choreographers, but rather focus on developing dancers. Yet while this argument has some merit, many of our participants felt that classical ballet training was a crucial stepping stone on the path to becoming choreographers. Thus, having schools which can contribute to the development of both dancers and choreographers would presumably be ideal. Future research might consider dancers with training in other countries, including those with more traditionalist systems vs. those who have embraced more innovative approaches. In addition, it will be important to consider how these findings apply to other forms of classical ballet training, including at the local school level.

This study is the first to explore how vocational ballet training relates to the development of creativity in choreographers and in doing so, supports recent reports of the link between SDT and creativity in ballet (Nordin-Bates 2019). It is important to note that the present findings focus on just one of the three basic psychological needs (Ryan and Deci 2000), and competence and relatedness may also be important in facilitating creativity (Nordin-Bates 2019). The theoretically driven link between autonomy and creativity means it is possible to provide clear recommendations of how vocational dance schools can develop creativity.

In line with media reports (Jennings 2013) and academic research (Stinson 2005; Lehikoinen 2006; Meglin and Brooks 2012; Clegg, Owton, and Allen-Collinson 2017; Kelly 2017), there were numerous suggestions that autonomy was particularly thwarted in females, both directly through actions such as punishment and via indirect elements of the training environment, such as requiring the female corps de ballet to train for a greater number of hours. While the participants' perspectives highlighted the importance of opportunities based on skill rather than gender, the perspective that these opportunities were equal across gender remains in contrast to data which indicates a bias, at least in the United States (Kelly 2017).

Through inductive analysis, the study showed the importance of variety for creativity, in line with the view that creativity is related to openness to experience (Barron and Harrington 1981), and supporting teachers' descriptions of creativity in dance students (Clements and Redding 2019). Participants reported that early childhood experiences had provided them with interests that persisted throughout their ballet training, and that this variety served their later creativity as choreographers.

Finally, the results showed the importance of offering opportunity for creativity. While all participants supported the need for technique and preservation of history, they also identified moments and individuals who had provided opportunities for creativity. Again, these experiences align with other domains who note that technical training should be supplemented with clear chances to be creative (Daly 2015).

\section{Recommendations for Vocational Ballet Schools}

In order to provide autonomy support and the subsequent development of creativity, schools should provide choices for dancers in movement. Teachers might also offer students the chance to choose their own music, thus also encouraging variety. Furthermore, teachers can provide autonomy support by giving clear reasons as to why dance is taught in a particular way, in addition to classes and feedback which encourage reflection and critical engagement. Schools should be aware of potential gender imbalances, and find ways to actively encourage young women to express their ideas while feeling that their individuality and creativity are valued.

Ballet schools can also offer variety by exposing students to art forms beyond ballet and dance. They should 
encourage students to identify areas of personal interest, and actively encourage their pursuit, by providing opportunities to explore these interests such as choreographing to a chosen song, or using art or literature as a basis. Family members might also encourage continued engagement with creative activities outside of dance.

Those already successful in choreography were clear role models for our participants. Therefore, schools could provide opportunities through regular visits from choreographers. The results of this work show that the newest generation of choreographers understand the need for autonomy support to nurture creativity, so engaging with these people will provide opportunities to young dancers. Inviting an equal balance of male and female choreographers might also make an important statement. In addition, schools could consider frequent choreographic workshops, but make these noncompetitive to encourage a processrather than product-focus.

In conclusion, this study demonstrates that the intrinsic motivation to create dance is impacted by experiences of classical ballet training. Dancers can be inspired to pursue a choreographic career through autonomy support, exposure to cultural variety, and through the provision of opportunities at all stages of their careers. It is important to note that the drive to create may exist pre-training, so it should be schools' responsibilities to create an environment whereby that interest can be explored and grow. Schools must be aware of the need for young women to pursue choreography and provide the resources to develop these skills. Doing so will enable more young dancers to experience a feeling of freedom in their training, hone creativity, and open up the possibility for more dancers to pursue their drive to choreograph.

\section{Notes}

1. Isabelle Vail, Director of Research, Dance Data Project, e-mail to author, February 4, 2020.

2. Nederlands Dans Theater.

\section{Acknowledgments}

We are very grateful to our participants who freely shared their time and experiences for the purposes of this study.

\section{Disclosure Statement}

No potential conflict of interest was reported by the authors.

\section{ORCID}

Lucie Clements (D) http://orcid.org/0000-0001-5924-8025

Sanna M. Nordin-Bates (D) http://orcid.org/0000-0003-34286900

\section{References}

Alterowitz, Gretchen. 2014. “Toward a Feminist Ballet Pedagogy: Teaching Strategies for Ballet Technique Classes in the Twenty-First Century." Journal of Dance Education 14 (1):8-17. doi:10.1080/15290824.2013.824579.

Amabile, Teresa M., and Jennifer S. Mueller. 2007. "Studying Creativity, Its Processes, and Its Antecedents: An Exploration of the Componential Theory of Creativity." In Handbook of Organizational Creativity, edited by Jing Zhou and Christina Shalley, 33-64. Mahwah, NJ: Erlbaum.

Amabile, Teresa M., and Julianna Pillemer. 2012. "Perspectives on the Social Psychology of Creativity." The Journal of Creative Behavior 46 (1):3-15. doi:10.1002/ jocb.001.

Barr, Sherrie. 2013. "Learning to Learn: A Hidden Dimension within Community Dance Practice." Journal of Dance Education 13 (4):115-21. doi:10.1080/15290824.2012.754546.

Barr, Sherrie, and Wendy Oliver. 2016. "Feminist Pedagogy, Body Image, and the Dance Technique Class." Research in Dance Education 17 (2):97-112. doi:10.1080/14647893.2016.1177008.

Barron, Frank, and David M. Harrington. 1981. "Creativity, Intelligence, and Personality." Annual Review of Psychology 32:439-476.

Benn, Tansin. 2003. "Reflections on a Degree Initiative: The UK's Birmingham Royal Ballet Dancers Enter the University of Birmingham." Research in Dance Education 4 (1):5-16. doi:10.1080/14647890308304.

Braun, Virginia, and Victoria Clarke. 2006. "Using Thematic Analysis In Psychology." Qualitative Research in Psychology 3 (2):77-101. doi:10.1191/1478088706qp063oa.

Choi, Euichang, and Na-Ye Kim. 2015. "Whole Ballet Education: Exploring Direct and Indirect Teaching Methods." Research in Dance Education 16 (2):142-60. doi:10.1080/14647893.2014.950643.

Clegg, Helen, Helen Owton, and Jacquelyn Allen-Collinson. 2016. "The Cool Stuff!: Gender, Dance and Masculinity." Psychology of Women Section Review 18 (2):6-16. doi:10.1080/14647893.2017.1391194.

Clegg, Helen, Helen Owton, and Jacquelyn Allen-Collinson. 2017. "Challenging Conceptions of Gender: UK Dance Teachers' Perceptions of Boys and Girls in the Ballet Studio." Research in Dance Education 19 (2):128-39. doi:10.1080/14647893.2017.1391194.

Clegg, Helen, Helen Owton, and Jacquelyn Allen-Collinson. 2019. "Attracting and Retaining Boys in Ballet: A Qualitative Study of Female Dance Teachers." Journal of Dance Education 19 (2):1-10. doi:10.1080/15290824.2018.1472381.

Clements, Lucie, and Emma Redding. 2019. "Creativity in Higher Education Contemporary Dance: An Interpretative Phenomenological Analysis." Journal of Dance Education 1-11. doi:10.1080/15290824.2019.1572155.

Cropley, David H. 2017. "Nurturing Creativity in the Engineering Classroom." In Nurturing Creativity in the 
Classroom, edited by Ronald A. Beghetto and James C. Kaufman, 212-26. New York, NY: Cambridge University Press.

Daly, Shanna R., Erika A. Mosyjowski, and Colleen M. Seifert. 2019. "Teaching Creative Process Across Disciplines." Journal of Creative Behavior 5 (1):5-17. doi:10.1002/jocb.158.

Dyer, Becky. 2009. "Merging Traditional Technique Vocabularies with Democratic Teaching Perspectives in Dance Education: A Consideration of Aesthetic Values and Their Sociopolitical Contexts." The Journal of Aesthetic Education 43 (4):108-23. doi:10.1353/jae.0.0056.

Gard, Michael. 2006. Men Who Dance: Aesthetics, Athletics and the Art of Masculinity. New York, NY: Peter Lang Publishers.

Jackson, Jennifer. 2005. "My Dance and the Ideal Body: Looking at Ballet Practice from the Inside Out." Research in Dance Education 6 (1-2):25-40. doi:10.1080/14617890500373089.

Jennings, Luke. 2013. "Sexism in Dance: Where Are All the Female Choreographers?” The Guardian, April 28. https:// www.theguardian.com/stage/2013/apr/28/women-choreogra phers-glass-ceiling.

Kelly, Colette. 2017. "Dancing up the Glass Escalator: Institutional Advantages for Men in Ballet Choreography." Columbia Undergraduate Research Journal 2 (1):1-46.

Lakes, Robin. 2005. "The Messages behind the Methods: The Authoritarian Pedagogical Legacy in Western Concert Dance Technique Training and Rehearsals." Arts Education Policy Review 106 (5):3-20. doi:10.3200/AEPR.106.5.3-20.

Lehikoinen, Kai. 2006. Stepping Queerly? Discourses in Dance Education for Boys in Late 20th Century Finland. Bern, Switzerland: Verlag Peter Lang.

Lo Iacono, Valeria, Paul A. Symonds, and David H. K. Brown. 2016. "Skype as a Tool for Qualitative Research Interviews." Sociological Research Online 21 (2):1-15. doi:10.5153/sro.3952.

Mead, David. 2009. "A Creative Ethos: Teaching and Learning at the Cloud Gate Dance School in Taiwan." Global Perspectives on Dance Pedagogy: Research and Practice, Conference Proceedings of the Congress on Research in Dance 41 (S1):278-83.

Meglin, Joellen A., and Lynn Matluck Brooks. 2012. "Where Are All the Women Choreographers in Ballet?" Dance Chronicle 35 (1):1-7. doi:10.1080/01472526.2011.650617.
Morris, Geraldine. 2003. "Problems with Ballet: Steps, Style and Training." Research in Dance Education 4 (1):17-30. doi:10.1080/14647890308308.

Nordin-Bates, Sanna M. 2019. "Striving for Perfection or for Creativity: A Dancer's Dilemma?" Journal of Dance Education 1-12. doi: 10.1080/15290824.2018.1546050.

Patton, Michael Q. 2002. Qualitative Evaluation and Research Methods. Thousand Oaks, CA: Sage.

Pickard, Angela. 2012. "Schooling the Dancer: The Evolution of an Identity as a Ballet Dancer." Research in Dance Education 13 (1):25-46. doi:10.1080/14647893.2011.651119.

QSR International. 2014. Nvivo Qualitative Data Analysis Software (QSR International Pty Ltd. Version 10).

Quested, Eleanor, and Joan L. Duda. 2011. “Antecedents of Burnout among Elite Dancers: A Longitudinal Test Basic Needs Theory." Psychology of Sport and Exercise 12 (2):159-67. doi:10.1016/j.psychsport.2010.09.003.

Ryan, Richard M., and Edward L. Deci. 2000. "Self-Determination Theory and the Facilitation of Intrinsic Motivation, Social Development, and Well-Being." American Psychologist 55 (1):68-78. doi:10.1037/0003-066X.55.1.68.

Salosaari, Paula. 2001. Multiple Embodiment in Classical Ballet: Educating the Dancer as an Agent of Change in the Cultural Evolution of Ballet. Helsinki, FIN: Theatre Academy.

Schwab, Kristin. 2016. "What Makes a Principal?" Dance Magazine, September. http://dancemagazine.com/inside$\mathrm{dm} /$ magazine/what-makes-aprincipal.

Sternberg, Robert J. 2007. "Creativity as a Habit." In Creativity: A Handbook for Teachers, edited by A.G. Tan, 3-25. Singapore: World Scientific.

Stinson, Susan W. 2005. "The Hidden Curriculum of Gender in Dance Education." Journal of Dance Education 5 (2):51-57. doi:10.1080/15290824.2005.10387285.

Watson, Debbie, Sanna M. Nordin-Bates, and Kerry Chappell. 2012. "Facilitating and Nurturing Creativity in Pre-Vocational Dancers: Findings from the UK Centres for Advanced Training." Research in Dance Education 13 (2):153-73. doi:10.1080/14647893.2012.694415.

Weidmann, Chelsea. 2018. "A New Dialogue in Ballet Pedagogy: Improving Learner Self-Sufficiency through Reflective Methodology." Journal of Dance Education 18 (2):55-61. doi:10.1080/15290824.2017.1346798. 